\title{
Клинико-морфологические особенности хламидийной пневмонии: анализ случая
}

1 - НУЗ "Дорожная клиническая больница ОАО "РЖД": 195271, Санкт-Петербург, пр-т Мечникова, 27;

2 - ГОУ ВПО "Санкт-Петербургская государственная медицинская академия им. И.И.Мечникова": 195067, Санкт-Петербург, Пискаревский пр-т, 47

\section{N.F.Levin, I.M.Skipsky, V.G.Radchenko, G.P.Smulskaya, M.M.Kharchenkova \\ Clinical and morphological features of pneumonia caused by Chlamydia: case analysis}

Key words: Chlamydia, pneumonia, pathomorphology, immune disorders, antibacterial therapy, immune therapy

Ключевые слова: хламидийная пневмония; патоморфология; иммунные нарушения; антибактериальная терапия; иммуномодулирующая терапия.

Chlamydophila pneumoniae в качестве возбудителя острых инфекций дыхательных путей была впервые описана в 1986 г. J.T.Grayston et al. [1]. Хламидийная пневмония относится к атипичным вследствие особенностей дебюта заболевания [2], или, как говорят в последние годы, "атипичности" возбудителей [3]. В этом случае этиологическая диагностика посредством рутинных методов (бактериоскопии и посева мокроты) неинформативна, наиболее точный результат обеспечивает полимеразная цепная реакция (ПЦР) [4-6].

Этиотропная терапия пневмонии невозможна без точного этиологического диагноза, а неэффективность начальной (эмпирической) антибактериальной терапии, как правило, приводит к ее последующей излишней интенсивности, повышающей вероятность лекарственного повреждения легких [7-9], но не гарантирующей подавления возбудителя. Это противоречие отчетливо проявилось в наблюдаемом нами случае заболевания хламидийной пневмонией, завершившемся летальным исходом.

Пациент К., 54 года, госпитализирован 11.11.05. За 3 нед. до госпитализации был вакцинирован против гриппа, после чего появились слабость, ломота в теле. За 1 нед. до госпитализации появились одышка, покашливание и озноб, температура тела повысилась до $38,0{ }^{\circ} \mathrm{C}$. Врачом поликлиники были назначены Антигриппин, Трависил и амоксициллин, прием которых самочувствия не улучшал. Флюорографически выявлена пневмония, в связи с чем пациент был госпитализирован.

В анамнезе: с 52 лет - аутоиммунный тиреоидит (АИТ), эутиреоз; эпидемиологический и аллергологический анамнезы не отягощены; больной не курил, алкоголем не злоупотреблял.

При поступлении состояние средней тяжести, пациент астенизирован, выражен гипергидроз. Цвет кожи и слизистых нормальный. Щитовидная железа диффузно умеренно увеличена (II степень), плотная. Периферические лимфоузлы не увеличены. Пульс - 100 мин $^{-1}$, ритмичный; артериальное давление (АД) $120 / 70$ мм рт. ст. Частота дыхания $-18-20$ мин $^{-1}$ в покое, 22-24 мин ${ }^{-1}$ - при небольшой физической нагрузке. Границы сердца не изменены, тоны приглушены, шумов нет. Грудная клетка обычной формы. Голосовое дрожание симметричное, усилено над нижними отделами легких, где укорочен перкуторный звук и выслушиваются мелкопузырчатые хрипы. Живот мягкий, без- болезненный. Печень не увеличена. Селезенка и почки не пальпируются.

По результатам анализа крови получены следующие показатели: гемоглобин - 127 г/л, лейкоциты - 18,7×109/л, эзинофилы $1 \%$, миелоциты - $1 \%$; палочкоядерные нейтрофилы - $7 \%$; сегментоядерные нейтрофилы - 73 \%; лимфоциты - $12 \%$; моноциты $-7 \%$; СОЭ - 32 мм/ч. Белок - 63 г/л; альбумин $-42,0 \%$, глобулин: $\alpha_{1}-7,7 \%, \alpha_{2}-17,0 \%, \beta-13,4 \%, \gamma-19,9 \%$; фибриноген 4,25 г/л, С-реактивный белок - 42 мг/л. Прочие биохимические показатели были в норме. При анализе мочи патология не выявлена. Анализ мокроты не производили, т. к. кашель был непродуктивным. Посредством электрокардиографии обнаружена синусовая тахикардия $\left(109\right.$ мин $\left.^{-1}\right)$ и диффузные изменения в миокарде. По данным эхокардиографии, полости сердца не расширены, миокард не утолщен, глобальная сократительная способность сохранена. При рентгенографии грудной клетки выявлена интенсивная инфильтрация в нижних отделах легких с 2 сторон (рис. 1). Результат фибробронхоскопического исследования - умеренно выраженный 2-сторонний слизисто-гнойный эндобронхит.

Установлен следующий клинический диагноз:

- основной: 2-стороняя пневмония (?), постпрививочный альвеолит (?);

- сопутствующий: АИТ, эутиреоз;

- осложнение: острая дыхательная недостаточность (ОДН) IІ степени.

Назначенное лечение (амоксициллин / клавулановая кислота 1,2 г 2 раза в сутки внутривенно болюсно, гепарин - 5000 Ед. 4 раза в сутки подкожно, кларитромицин - 250 мг 2 раза в сутки per os,

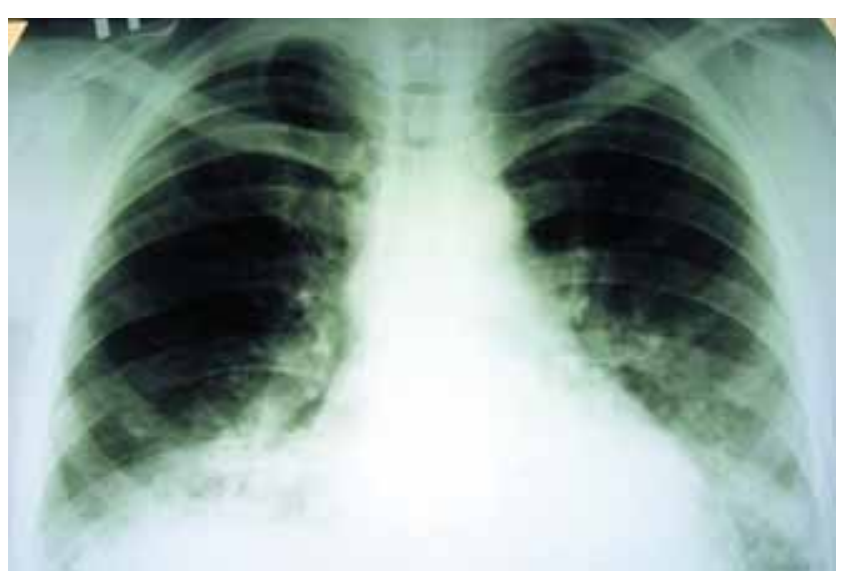

Рис. 1. Рентгенограмма грудной клетки пациента К. в день госпитализации 


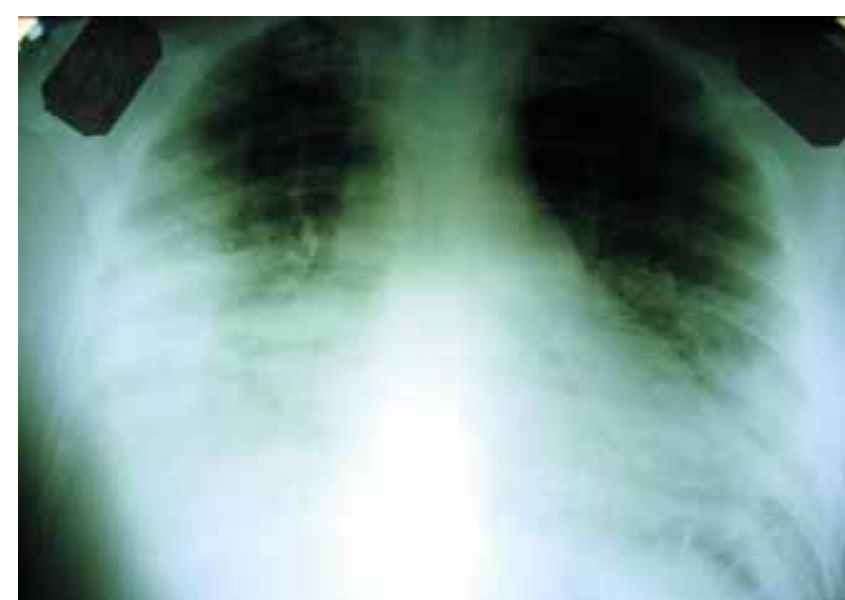

Рис. 2. Рентгенограмма грудной клетки пациента К. на 9-й день стационарного лечения

преднизолон - 10 мг 2 раза в сутки per os, L-тироксин - 75 мкг в сутки per os) в течение 3 дней улучшения не принесло, в связи с чем на 4-е сут. стационарного лечения вместо амоксиклава и кларитромицина назначены ципрофлоксацин (500 мг 2 раза в сутки per os) и цефазолин (1,0 г 2 раза в сутки внутримышечно), что также не привело к улучшению. На 7 -е сут. эти препараты были заменены на цефоперазон (2,0 г 2 раза в сутки внутривенно инфузионно в $0,9 \%$-ном растворе $\mathrm{NaCl}$.

На 9-е сут. состояние пациента резко ухудшилось, усилилась одышка: дыхание частое и поверхностное, 28 мин $^{-1}$, временами до 40 мин $^{-1}$. Появился диффузный цианоз с акроцианозом. Пульс 110 мин $^{-1}$, АД - 110 / 70 мм рт. ст. Тоны сердца глухие. Аускультативно дыхание жесткое, в нижних отделах - крепитация.

Срочно выполненная рентгенограмма грудной клетки показала, что понижение прозрачности обоих легочных полей в средненижних отделах стало более интенсивным (рис. 2).

Пациент переведен в отделение реанимации и интенсивной терапии, где его состояние, несмотря на интенсивную терапию, не улучшалось и было расценено как пограничное вследствие острого респираторного дистресс-синдрома (ОРДС). Начата респираторная аппаратная поддержка, обеспечившая сатурацию крови кислородом на уровне $75 \%$, но на этом фоне синусовый ритм сменился идиовентрикулярным с частотой сердечных сокращений 30 мин $^{-1}$ и последующими фибрилляцией желудочков и асистолией. Реанимационные мероприятия оказались неэффективны. Констатирована биологическая смерть.

Заключительный (посмертный) клинический диагноз:

- основной: внегоспитальная 2-сторонняя вирусно-бактериальная пневмония;

- конкурирующий: бронхиолоальвеолярный рак в пневмониеподобной форме (?);

- осложнения: ОРДС, ОДН ІІІ степени;

- сопутствующий: АИТ, эутиреоз.

Поводом заподозрить бронхиолоальвеолярный рак, несмотря на непродуктивность кашля у пациента, послужило прогрессирующее течение заболевания на фоне интенсивной антибактериальной терапии.

Выписка из протокола патологоанатомического исследования: "Легкие увеличены в объеме, маловоздушные, на ощупь диффузно уплотнены, на разрезе зернистого вида, красновато-серые, с обильным полупрозрачным отделяемым, кусочки их тонут в растворе формалина".

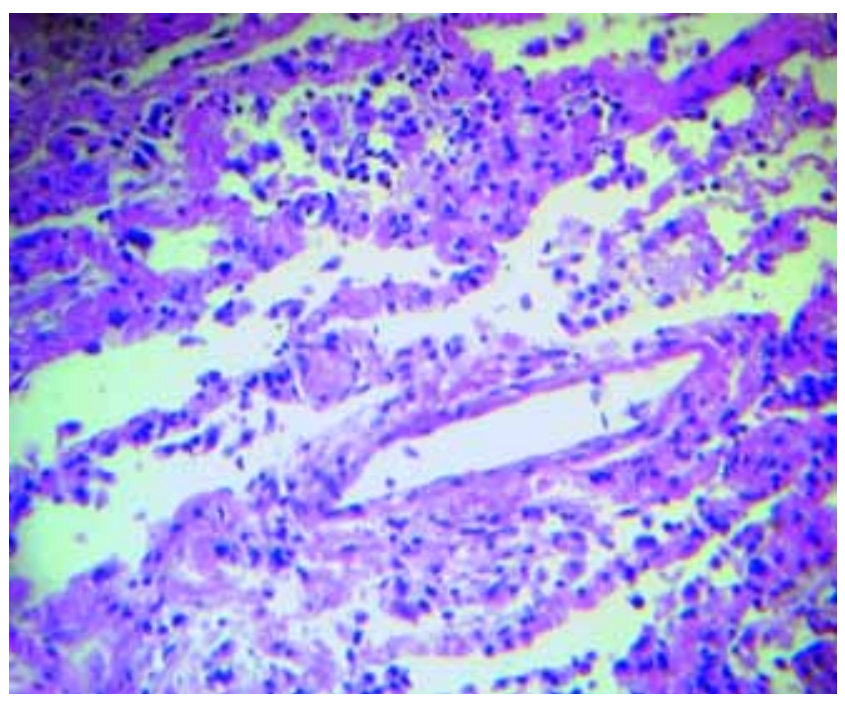

Рис. 3. Микрофото препарата легкого умершего пациента К (описание в тексте). Окраска гематоксилином и эозином; $\times 150$

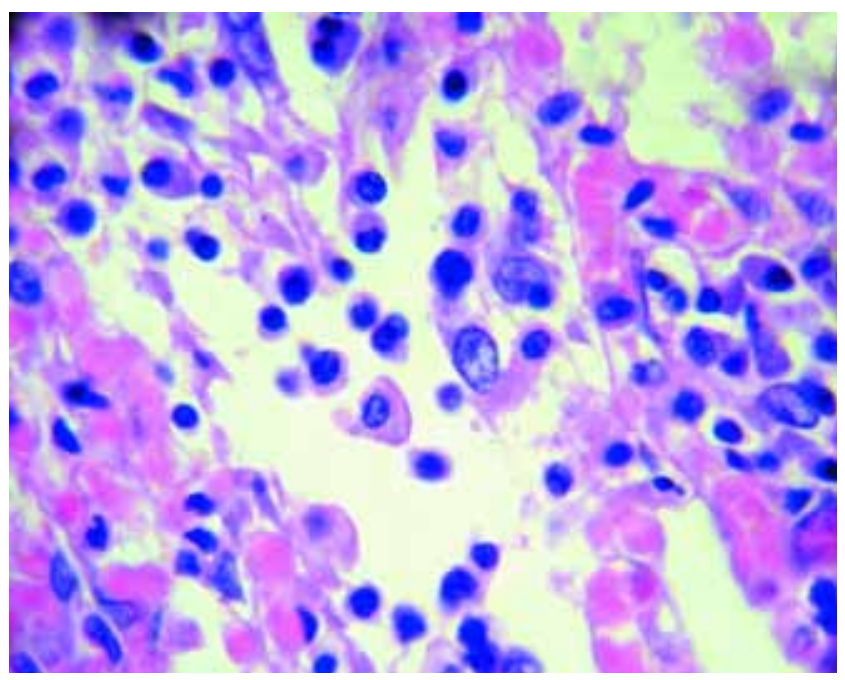

Рис. 4. Микрофото препарата легкого умершего пациента К. (описание в тексте). Окраска гематоксилином и эозином; $\times 400$

Выписка из протокола гистологического исследования ткани легких: "Эпителий большинства бронхов десквамирован, слизистая оболочка с нерезко выраженной круглоклеточной инфильтрацией. В просвете практически всех альвеол - макрофагально-белковый экссудат, часто с наличием гиалиновых мембран - то узких, прерывистых, то достаточно крупных, сплошных. Резко выраженная пролиферация альвеолярного эпителия с гигантоклеточной метаплазией, выраженным ядерным полиморфизмом клеток (гиперхроматоз части ядер, матовость отдельных, вакуолизация части ядер, мелкая зернистость). Цитоплазма макрофагальных клеток зернисто-вакуольная, пенистая. Очаговые скопления плазматических клеток. Круглоклеточная инфильтрация части межальвеолярных перегородок. Участки отека" (рис. 3, 4).

Проведено исследование трупного материала. В крови (в сравнении со взятой прижизненно) титры антител против штаммов вирусов гриппа A1, A2, B, парагриппа I-III не наросли, антитела

Таблица

Результаты вирусологического исследования (титры антител) сыворотки крови

\begin{tabular}{|l|ccc|ccc|c|c|}
\multicolumn{1}{|c|}{ Антиген } & \multicolumn{3}{|c|}{ Грипп } & \multicolumn{3}{c|}{ Парагрипп } & Аденовирус & Респираторно-синцитиальный вирус \\
\hline Штаммы & А1 & А2 & В & I & II & III & - & - \\
\hline 1-я сыворотка & 160 & 80 & 160 & 40 & 40 & 40 & 0 & 0 \\
\hline 2-я сыворотка & 160 & 80 & 160 & 40 & 40 & 40 & 0 & 0 \\
\hline
\end{tabular}


против аденовируса и респираторно-синцитиального вируса отсутствуют (таблица). Методом реакции иммунофлюоресценции в трахее и бронхах выявлены включения хламидий, методом полимеразной цепной реакции (ПЦР) - ДНК Chlamydophilae pneumoniae. Возбудители орнитоза и SARS методом ПЦР не обнаружены.

Патологоанатомический диагноз:

- основное заболевание: 2-сторонняя тотальная хламидийная пневмония (возбудитель - Ch. pneuтопіае);

- осложнения: ОРДС, прогрессирующая ОДН, паренхиматозная дистрофия миокарда, печени, почек;

- сопутствуюшие заболевания: АИТ;

- причина смерти: ДН.

На основании анализа приведенного случая можно сделать следующие практические выводы:

1. Для хламидийной пневмонии характерно не гнойное, а преимущественно пролиферативнометапластическое поражение бронхиолярного и альвеолярного эпителия, сочетающееся со слизисто-гнойным эндобронхитом.

2. Развитию и прогредиентному течению хламидийной пневмонии могут способствовать иммунные нарушения, в данном случае предшествовавшие АИТ, и иммунная перестройка после эффективной противогриппозной вакцинации (стабильно высокий титр антител против разных штаммов вируса гриппа и парагриппа).

3. Неэффективность 6 антибиотиков в течение 16 дней в данном случае является следствием нарушения режима терапии: при атипичных пневмониях лечение следует начинать с препаратов 1-го ряда - макролидов и тетрациклинов [2] - либо немедленно применять их, если другие антибиотики оказались неэффективными. Необходимо использовать ПЦР для уточнения возбудителя.

4. При хламидийной пневмонии, особенно при очевидном или вероятном иммунном дисбалансе, необходима иммуномодулирующая терапия, одним из вариантов которой может быть применение рекомбинантного интерлейкина-2 человека, высокоэффективного в подобных случаях [10].

\section{Литература}

1. Grayston J.T., Kuo C.C., Wang S.P. et al. A new Chlamydia psittaci strain called TWAR from acute respiratory tract infections. N. Engl. J. Med. 1986; 315 (3): 161-168.
2. Lynch J.P. III, Toews G.B. Community-acquired pneumonia. In: Khan M.G., ed. Cardiac and pulmonary management. London: Lea\&Febiger; 1993. 618-635.

3. Синопальников А.И. Внебольничные инфекции нижних дыхательных путей. В кн.: Чучалин А.Г., Синопальников А.И., Страчунский Л.С. Пневмония. М.: ООО "Медицинское информационное агенство"; 2006. 17-49.

4. Екимов А.Н. Детекция возбудителей атипичной пневмонии. В кн.: Чучалин А.Г., Синопальников А.И., Страчунский Л.С. Пневмония. М.: ООО "Медицинское информационное агенство"; 2006. 84-88.

5. Тартаковский И.С. Современные подходы к диагностике атипичных пневмоний. Клин. микробиол. и антимикроб. химиотер. 2000; 2: 60-68.

6. Murdoch D.R. Nucleic acid amplification tests for the diagnosis of pneumonia. Clin. Infect. Dis. 2003; 36: 1162-1170.

7. Данциг И.И., Скипский И.М., Смульская Г.П. Затяжная пневмония: факторы риска и лечебная тактика. Тер. apx. 1999; 71 (3): 32-35.

8. Хоигни Р., Хопф Б., Зоннтаг Р. Пенициллины, цефалоспорины и тетрациклины. В кн.: Дюкс М.Н.Г. (ред.). Побочные действия лекарственных средств: Пер. с англ. М.: Медицина; 1983. 274-303.

9. Steigel D., Bubendorf L., Oberholzer M. et al. Ciprofloxacininduced acute interstitial pneumonitis. Eur. Respir. J. 2004; 23 (1): 172-175.

10. Мусалимова Г.Г., Саперов В.Н., Карзакова Л.М. и др. Клинико-иммунологическая оценка эффективности ронколейкина при микоплазменной и хламидийной пневмонии. Пульмонология 2004; 3: 25-31.

\section{Информация об авторах}

Левин Николай Федорович - зав. патологоанатомическим отделением НУЗ "Дорожная клиническая больница ОАО "РЖД", врач-патологоанатом высшей категории; тел.: (812) 543-30-13

Скипский Игорь Михайлович - к. М. н., доцент кафедры внутренних болезней с курсом терапии и нефрологии факультета повышения квалификации ГОУ ВПО "Санкт-Петербургская государственная медицинская академия им. И.И.Мечникова"; тел.: (812) 543-05-86

Радченко Валерий Григорьевич - д. М. н., проф., зав. кафедрой внутренних болезней с курсом терапии и нефрологии факультета повышения квалификации ГОУ ВПО "Санкт-Петербургская государственная медицинская академия им. И.И.Мечникова"; тел.: (812) 543-05-90

Смульская Галина Павловна - зав. пульмонологическим отделением НУЗ "Дорожная клиническая больница ОАО "РЖД", врач-пульмонолог высшей категории; тел.: (812) 543-60-23

Харченкова Марина Михайловна - ординатор пульмонологического отделения НУЗ "Дорожная клиническая больница ОАО "РЖД", врачпульмонолог высшей категории; тел.: (812) 543-60-23

Поступила 27.02.08 () Коллектив авторов, 2009 УдК 616.24-002:579.882 